\title{
Diversity, fluidity and threats to social identity: The case of ELT in Oman
}

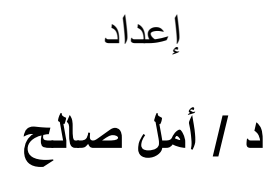

\begin{abstract}
The developing structure of Omani higher education sector sustains its dependence on culturally diverse staff body that constitutes a majority as opposed to locals. This creates unique group composition that is inconsistent with the largely Omanizing workplace context. Drawing on data gathered from a case study, this paper explores the effects of group instability resulting from faculty's cultural diversity on establishing a group's social identity. The findings of the study suggest that cultural diversity is associated with a number of factors that impede longevity within a group thus affecting identification with a common prototype. These factors include human resources management practices, such as outsourcing recruitment, inconsistent recruitment standards, low faculty agility and a number of individual factors that forefront individual identity. The paper concludes by arguing that the absence of social identity in higher education hinders establishing an intellectual capital in Omani higher education that aims to promote research and innovation as cornerstones for establishing a knowledge-based economy. The findings have implications to the GCC contexts that are characterised by depending on largely culturally diverse workforce.
\end{abstract}

Key words: Omanization, prototypicality, cultural diversity, longevity, higher education, intellectual capital

\section{Introduction and Background}

When the new Omani state was established in 1970, the workforce was mainly composed of Omanis who represented $93 \%$ of the civil service workers. As the requirements of establishing a new state were far beyond the local capacity then, the government resorted to importing trained labor and experts qualified in various areas. As a result, the number of nonOmani employees rose to $32 \%$ by 1993 (Al-Hamadi et al., 2007). The repercussion of such an increase became evident over time especially with regards to the increasing number of unemployed locals. Aiming to mitigate this effect, the government embarked on a process of nationalizing its workforce, locally known as 'Omanisation', in 1988 (Peterson, 2011; Zerovec \& Bontenbal, 2011). The policy aims to gradually replace international workforce with trained nationals that would constitute $95 \%$ of the public sector employees and $75 \%$ of the private sector's by 2020 (Donn \& Issan, 2007).

The imperative to achieve the Omanisation objectives created a need for developing national human resources through providing better education and better service training (Al Balushi, 2012). Among other things, this has led to the expansion of higher education (HE) and technical and vocational training institutions that aim to prepare graduates for a diversifying economy (Al-Hamadi et al., 2007). Such an expansion, however, led to importing more academics to teach these programs (Abbas, 1995), which has sustained the cultural diversity of faculty in higher education institutions (HEIs) and raised questions about the feasibility and 
practicality of Omanisation in this sector. Such a status of flux also raises questions about the extent to which workgroups in higher education enable this sector to respond to the national expectations from a social psychological perspective.

Aiming to explore the reasons leading to staff instability in the culturally diverse HE context in Oman and the influence of that on establishing a social identity, this paper starts by exploring the human resource composition in the Omani higher education with specific focus on the context of English Language Teaching (ELT). It then interweaves concepts of intellectual capital theory and social identity theory to explain the importance of establishing a collective identity to creating an intellectual capital. The paper then presents the findings of a case study that illustrate the effects of lack of prototypicality resulting from group instability on group outcomes. It concludes by outlining the implications of these findings in relation to the ambitions of the Omani higher education in the current transformational phase of the Omani state development.

\section{Language, cultural diversity and identity in the Omani HE}

With the expansion of higher education provision in Oman, English has become the language of higher education institutions (Al-Issa, 2006). The prominent status of English in higher education required recruiting staff qualified in this field. As English is a foreign language in a country whose indigenous language is largely Arabic, the supremacy of English as the language of knowledge has created a level of friction between the demands of the process of Omanisation and the demands imposed by the adoption of English as the medium of instruction. These factors created a unique composition that characterized the context of ELT, which has now become an integral part of most HEI in Oman. In such contexts, Omanis constitute a small percentage among language teachers who belong to various Arab, Asian, African, and European countries (Al-Issa, 2005). Al-Mahrooqi \& Tuzlukova (2014) illustrates that the staff of the Language Centre in Sultan Qaboos University in Oman is composed of 30 nationalities. Such cultural diversity challenges the concept of social/group identity within higher education as it translates in diversity in the values, norms and behaviors within workgroups.

\section{Social/group identity and cultural diversity in ELT}

The Social Identity Approach (SIA) established by Tajfel and Turner defines a group as 'a collection of individuals who perceive themselves to be members of the same social category, share some emotional involvement in this common definition of themselves, and achieve some degree of social consensus about the evaluation of their group and their membership of it' (Tajfel \& Turner, 1979, 40). According to this perspective, the interaction between people falls within a continuum ranging from interpersonal (determined by individual characteristics) to intergroup (determined by the membership of certain group). Identification with a group slides self-concept, and hence behavior, towards the end of the continuum where the aspects of similarity, sharedeness and consensus are essential to the functioning of a group.

Based on this perspective, social identification entails that individuals perceive of the salient social category that underlies social identity as a prototypical cognitive image of the social group. Hogg $(2001,187)$ defines prototypes as 'context-specific, multidimensional fuzzy sets of attributes that define and prescribe attitudes, feelings, and behaviors that characterize one group and distinguish it from other groups'. Prototypes inform social identity through the process of depersonalization that transforms individual self-concept that is based on individual characteristics into a group-based self-concept informed by the group norms (Hornsey, 2008). Depersonalization happens when a cognitively salient social category 
constitutes the prototype that informs a group's behavior. Considering the cultural mix constituting Omani HE groups, the relevance of the concept of group could be challenged due to the salience of various cultural categories. While the SIA does not completely ignore the conceptualization of self based on individual characteristics, it largely ignores the possible interaction between individual identity and social/group identity.

Haslam \& Platow (2001) contend that the salience of a unified social identity (as opposed to individual identity) significantly influences behavior because it leads individuals to perceive themselves as representatives of the group and thus share its norms and goals. Individuals within a group could be seen as more prototypical or less prototypical depending on the extent to which they embody the group's characterizing prototype. The existence of various degrees of prototypicality within a group explains certain group behaviors such as sub-groups, deviance, and leader-follower status (Hogg, 2001). It also explains various group processes such as influence within a group, cohesion and conformity (Hornsey, 2008). Moreover, the salience of a social identity makes individuals share the perspective through which they perceive reality and it motivates them to align their behaviors with the norms of the group. Also, it encourages collaborative work among group members that is based on the group's objectives (Haslam \& Platow, 2001).

\section{Group identity and the vision of Omani higher education}

Given the influence of a salient social identity on a group's functioning, the question regarding the existence of social identity among the culturally diverse HE faculty in Oman pertains. While the literature suggests that the academic discipline could form the basis for group identity in academia (Blackwell et al., 2009; Clarke et al., 2013; Schmaling et al., 2014), the mix of cultural identities characterizing Omani HE is likely to hinder the salience of a unified academic/professional identity. This is especially so that academic faculty members are mostly non-Omanis, which means that longevity within the group could be affected by the constant movement of members from and to the group.

However, the Omani higher education that functions as the tool for enabling the diversification of the Omani economy from oil-based to knowledge-based can only face the demands of managing staff diversity towards a form of social identity. This is especially so due to the yet insufficient local academic capacity. Khalique, Shaari, \& Isa (2011) argue that value in knowledge-based economy lies in building intellectual capital through the investment in managing faculty. Kelly's (2004) presents a typology of intellectual capital that could be achieved through three main means: competence, attitude, and intellectual agility as in figure 1. In light of this model, the investment in staff cultural diversity happens when staff members' tacit knowledge and experiences are transformed into explicit knowledge that is shared and utilised within the HEIs. This process is mediated by factors at the level of the leadership of the HEIs that moderate the effects of intellectual agility and attitude capital. Kelly considers faculty's attitude as a key factor in this process but he believes that it is difficult to harness attitudes towards transferring competence from tacit to explicit. 


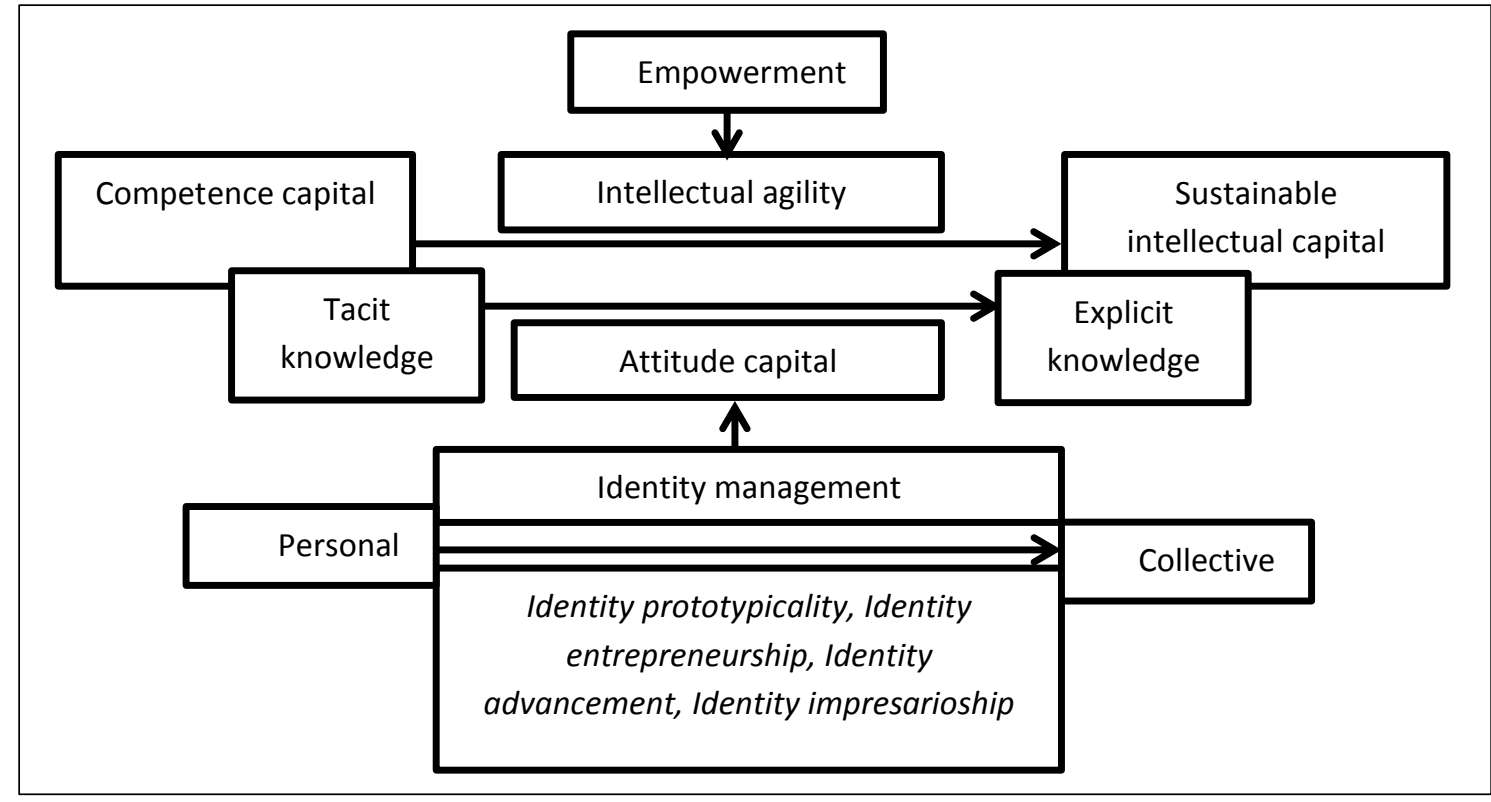

Figure 1: Higher education intellectual capital model

A social identity perspective would suggest, however, that for competent faculty members to invest themselves in serving the interest of the group (the HEI in this context), they would need to perceives that group as a salient form of self-concept (van Knippenberg \& Hogg, 2003). Ellemers et al., (2004:461) stress that 'a self-conception in collective terms would energize people to exert themselves on behalf of the group, facilitate the direction of efforts towards collective (instead of individual) outcomes, and help workers sustain their loyalty to the team or organization'. Nonetheless, Kramer (2006) argues that for individuals to identify with a collective group and produce group-oriented behaviour, the salience of contextual cues is an antecedent.

In organisational contexts such as that of the Omani higher education, this means that the onus is on HEIs to capitalise on building a level of group identity in order to contribute to achieving the vision of the new Omani state. Steffens et al. (2014) argue that organizations could establish a collective identity through strategies to establish identity prototypicality, identity entrepreneurship, identity advancement and identity impresarioship. In brief, such strategies entail investing in practices that make individuals identify with an organizational collective identity. Such practices include, but are not limited to, creating an inclusive context an establishing a level of similarity and groupness. Transforming faculty's attitudes to serve the purpose of the Omani HE could mediate the effect of competence on creating an intellectual capital through enabling knowledge transformation. When a collective identity is made salient, perceptual, motivational, and evaluative behaviors echo the norms underlying the collective identity. However, the salience of a social identity could threaten individual's intellectual agility as it entails that prototypicality and conformity are main features of social identification. This suggests that a balance needs to be achieved between the collective and individual identity levels so that higher education can utilise cultural diversity for building intellectual capital. Maintaining such a balance should be one constituent of the group's prototype. 


\section{Methodology}

Tatli and Özbilgin (2012) argue that research on identity should remain open to contextspecific constructions of identity rather than viewing categories as objective realities that are not influenced by power relations. Identities are not distinct entities, which challenges the concept of identity salience as advocated by the SIA. The intersectionality theory suggests that identities 'interact with each other to create specific manifestations that cannot be explained by each alone' (Warner, 2008:454). In addition, Haslam $(2004,27)$ argues that 'the application of social identity to organizational settings clearly needs to be sensitive to features of social psychological context'. The centrality of the context is attributed to its role in shaping how people behave, think and feel and thus understanding the context where individuals construct their identities is key for understanding them (Gillham, 2000).

Therefore, this study deploys a case study design to look at the complexity of identity within academic workgroups. Case study is powerful in that it enables deep understanding that is aided by the use of multiple methods. In specific, the study investigates the case of ELT and draws on data collected from an English Department at a College of Applied Sciences (henceforth CAS-1) in Oman. This college is part of a network of six campuses that function under the jurisdiction of the Ministry of Higher Education. Strategically, the CASs are guided by the Ministry of Higher Education's (MoHE) vision that aims to use them as platforms for 'providing practical and innovative solutions for the ever-changing local and national needs' (Ministry of Higher Education, 2015). Thus, CAS colleges are versatile in nature and reshuffle repeatedly as to maintain such flexibility.

This paper reports findings that are part of a bigger project conducted in 2016. The project employed triangulated sources of data that consisted of sixteen interviews, eight meeting observations, document analysis, field notes and indirect observations to explore group dynamics and the construction of identity in the Omani culturally diverse HE. This paper largely draws on data generated from the 16 interviews with culturally diverse staff members that aimed at investigating individual meanings. One-to-one interviews were conducted to explore perceived diversity; the reality of cultural diversity as perceived and experienced by the group members (Hentschel et al., 2013). By opting for investigating perceived diversity, the study avoids falling on the limitation of positivistic research that views social categories as homogenous entities and embraces the view that perceptions are key for understanding salience of identity (Jackson \& Sherriff, 2013).

Six interviews were conducted with teachers who had been part of the leadership team at a certain stage during their careers at CAS-1. The SIA considers leadership a key group process that influences individuals within a group towards becoming prototypical group members who act based on the social identity of the group (Hogg \& Reid, 2006). This group included five teachers who occupied the role of team/subject leaders at certain point of their career at CAS in addition to the HoD who is in charge of the whole Department. Furthermore, interviews with ten other regular teachers were conducted. Three relatively similar interview schedules were designed and piloted to investigate the perceptions of the team members, team leaders and the HoD. The semi-structured interviews with the participants lasted for an average of 75 minutes during which participants reflected on their experiences within the team and the extent to which they perceived the department to function as a group. The interviews were transcribed by the researcher and were coded using a descriptive coding technique which focused on the topic or idea expressed (Saldana, 2016). After that themes were generated guided by the SIA theory and the data gathered. 


\section{Researcher positionality}

The design of the study was influenced by a constructivist view that considers reality as multiple and socially constructed. Hence, my aim was to construct one version of reality using multiple means and voices. Creswell (2014:8) highlights that according to constructivism traditions, "researchers recognize that their own backgrounds shape their interpretation, and they position themselves in the research to acknowledge how their interpretation flows from their personal, cultural, and historical experiences'. I worked for over four years in the research site interacting with culturally diverse colleagues. Despite the extant debate in literature about the possible drawback of insider-research, Mercer (2007) cautions against viewing insiderness and outsiderness as dichotomies and urges that they instead should be viewed as ends of a continuum because the position of the researcher could vary depending on the aspect of identity in question.

I believe that my positionality has influenced many of my choices starting with shaping the interest in the research topic. It might have also influenced the decisions of the recruited participants although I had specific criteria for selecting them including the diversity of nationality, gender, roles and years of experience. I strived to minimize my influence over the flow of interactions and events in the research context to allow for the participants' own meanings to be constructed. Nonetheless, constructivist research does not cast away possible subjectivity as it considers reality as subjective and socially constructed. During the participant recruitment process, I provided the participants with the contact details of the Head of Research Governance at that University of Southampton to report any ethical breach I could intentionally or unintentionally commit using my positionality. During the interpretation I constructed meaning using the views of the different participant groups bearing in mind the possible differences associated with the different social categories.

\section{Anonymity, sensitivity and research on diversity}

Due to the potential sensitivity associated with diversity research (Dickson-Swift et al., 2008), participants were presented as anonymous and quotes from their narratives were presented using the scheme [code-role-nationality-employment type] to establish the themes. Fully concealing participants' identities was challenging because of the specific scope of case study research (Christians, 2008). The focal interest of this research is cultural diversity, which necessitates bringing aspects of the identities of the participants to the fore in reporting the case study. Such specificity could lead to the identification of respondents by those who know them personally as their contributions will reflect their individualized views (Lee, 1993). Also, intense description of context could compromise participants' anonymity.

Kelly (2009:10) stresses that 'anonymised research imposes a burden of care on the researcher-writer to maintain a balance between anonymity and illumination; to give only enough circumstantial specifics as are required to decipher the meaning (but not the identity) of the site and its characters'. To eliminate such possibility, I followed the advice of Creswell (2007), which suggests that the researcher should report the full picture rather than report individual pictures separately. I established a collective picture out of the data generated and strived to remain vigilant to balance the focus between identities and group dynamics at the context of the English Department as to avoid intense description that could easily identify participants or the specific CAS campus. Thus, findings in the report of the case are presented in a thematic structure rather than individual narratives. In using evidence from the interviews in the case report, the names of the participants are anonymised using the codes T1-T16. The researcher, however, has constructed full profiles for the participants, which is available with her only. 


\section{Findings}

The researched department included 27 teachers coming from 9 different countries. Recruitment at CAS is a central process that is managed by the MoHE in coordination with the recruiting agencies in the case of English Departments. Of these 27 teachers, $30 \%$ were recruited through MoHE permanent contracts and this category exclusively included 8 Omani staff members. In addition, 26\% were recruited through MoHE fixed contracts. Most staff members at the English Department were outsourced through recruiting agencies and this category exclusively comprised international staff including all the NESTs (12 teachers). Due to such a composition, the findings indicate that transience is the main characterizing feature of the staff body that, in association with the culturally diverse nature of the group, seemed to have hindered establishing a unified prototype. The data suggests that there are a number of factors that contributed to creating the transient composition.

\section{Contingent Membership}

$44 \%$ of the staff body in the English Department was outsourced through agency contracts. Outsourcing the majority of staff at the English Department seemed to have created a contingent category that is neither perceived as in-group nor out-group. Such a contingent status is a result of the temporary contract between the MoHE and the supplying agency, which has always put the membership of outsourced staff at stake due to the constant feeling of employment insecurity. T10's illustrates such insecurity by reporting the high anxiety she experienced at the end of her first contract with the recruiting agency before she was transferred to another sponsor.

... [Agency 1] seemed to be fairly confident that they'll get the contract and we would just continue on but it didn't ... So, everybody was looking for different jobs. I didn't know whether I should be packing all my things to leave Oman or whether I will be able to stay here in September...[T10, member, British, outsourced]

While the SIA considers the feeling of belonging to a group a key for identifying with that group, the findings suggest that such feeling is threaten by the employment insecurity. Such lack of employment security at the English Department affected motivation and accountability among staff. T15 emphasizes that because of the low longevity, some teachers do not see much value in investing time in teaching as they are more occupied with employment security concerns. The persistent feeling of insecurity among teachers resulted in a high voluntary turnover and affected the retention of professional teachers (especially native speakers) who 'are always unconfident about whether they will get the next contract or not. So, they start looking [for jobs]' [T15, member, Indian, MoHE-fixed].

Contrary to what the findings suggest, Joarder et al., (2015) report that there is no significant relation between perception of employment security and intention to leave. The researchers explain this by the young age of the academics they investigated in their study. They, however, provide no information about the cultural mix of their sample recruited from an academic context in Bangladesh. It could be that it is more common among expatriate to develop such turnover intentions as opposed to locals. In fact, the findings of this research suggest that Western teachers are more likely to have an intention to leave early because they have better employment opportunities elsewhere as NESTs. Also, settlement in one specific place for a long time is not a cultural norm for most western teachers.

On the other hand, Cole \& Bruch (2006) find that there is a negative correlation between organizational identification and turnover intentions among lower level workers, which suggests that low identification is a reason for high turnover. The temporary membership 
associated with outsourcing does not fulfill a person's motivation to identify with a specific prototype. Individual's quest for clarity, distinctiveness, and high self-esteem are the main reasons for such an identification (Hogg, 2005). Haslam (2004) states that when these motivations are not fulfilled, a person leaves the group in quest of joining another group that does fulfill them.

\section{Recruitment Standards}

There was a perception that the standards observed in recruiting English teachers are inconsistent and largely dependent on the employer. This resulted in recurrent recruitments and contract terminations due to low professionalism with many recruits. Based on the perceptions of the participants, professionalism is compromised when teachers are recruited based on being a NEST rather than based on their qualification in ELT. Lack of professionalism was associated more with the outsourced staff category to which all the NESTs belonged.

... there were a lot of unprofessional instructors who were worried about very immature things ...just creating unnecessary divisions. Not putting personal feelings aside for professionalism first... [T11, member, American, outsourced]

Professional identity in terms of being qualified in ELT provides a frame of reference that informs individual's behavior in such a context. However, such a frame of reference could be threatened by the cultural diversity. van Knippenberg \& Schippers (2007) indicate that the effects of diversity can follow a curvilinear pattern such that diversity becomes negative when it threatens the group's frame of reference. Cultural diversity in this context was associated with professional diversity. The frequent changes in the recruiting agencies, hiring professional teachers was seen as a matter of 'luck' as T4 [leader, Omani, MoHE- permanent] stressed. In fact, many teachers joined the English Department and left it during the probation period because of the observed low professional standards as illustrated by the Head of the Department.

She [one terminated teacher] spent one week with her students and we got feedback from the students .... that she would waste time to talk about totally off-topic [aspects] and sometimes she would do something culturally inappropriate ... this teacher has been fired six times before she came to this College ... and she also lied about her CV. [T6, HoD, Omani, MoHE-permanent]

Ashforth \& Johnson (2001) stress that making a higher order identity (such as professional identity here) salient could produce professional behavior, give priority to professional rather than individual goals, guide the interpretation of reality and enhance cooperation between individuals. The absence of such a higher order professional identity that is based on unified professional standards within the department contributed to increased instability.

\section{Low Faculty Agility}

The findings suggest that, especially among the non-Omani teachers, there was a perception that the CAS's organizational culture is rigid which causes dissatisfaction among teachers and raises turnover rate. Rigidness concerns the extent to which individuals are able to influence how things are done within a specific context. The English Program at CAS has a centralized curriculum that follows standardized practices across the different campuses. Centralized higher education governance could be effective in maintaining identity (Lo, 2010), which is one objective of education in Oman (Al'Abri, 2011). As centralization entails that decisions are made by fewer people within an organization (Anderson \& Brown, 2010), decision- 
making at the six English Departments is controlled by the Programme Director (PD).

Hierarchy-based leadership that is based on central decision-making is generally a characteristic of leadership ideology in Oman (Al-Hamadi et al., 2007). Within such an ideology, senior leadership sets the prototype that is expected to guide practices at the six English Departments that should conform to each other in terms of the program content, objectives, deadlines, and assessment. However, such top-down control over the prototype seemed to have suppressed the variability created by the cultural diversity within the department as T12 elaborates.

... a lot of teachers come with the idea of 'this structure is not good because I come from South Africa, I come from Australia, I come from wherever and let's change it a bit'...I think that is what frustrates teachers... they just get so angry and they just leave. [T12, member, South African, outsourced]

Thus, the imposed prototype seemed to have increased the rate of turnover and instability characterizing the group. This hinders establishing a shared understanding of what constitutes such a prototype. Neal (2010) also reports such dissatisfaction in his findings. He suggests that faculty members at a state HEI in Oman equally consider the organizational bureaucratic practices as a shared enemy. In higher education, however, organizations are expected to capitalize on the intellects and variability of ideas and approaches are usually seen as an asset. When wider perspectives are key to a task achievement, hierarchy could become a hurdle (Anderson \& Brown, 2010).

\section{Individual Motivations}

The findings also suggested that many NESTs seek employment in Oman for tourism purposes rather than for establishing a profession-based career. This created differences in objectives for joining the group and made personal objectives more salient than professional ones. The salience of personal objectives was perceived to affect teachers' performance at the professional level and the extent to which they pursue the development of a shared professional identity as stressed by T16.

If you are planning to have a career there, then you are planning long-term, then you care about self-development. You care about the improvement of you work, the prospects are more or less wider and clear in your mind and you've got plans and you are ready to compromise, you are ready to learn... but if $30 \%$ to $40 \%$ of the people you are working with you know that they are here for one or two years, then the problem is deeper and worse than just teamwork. [T16, member, Tunisian, MoHEfixed]

This perspective seems to agree with the view of Wong (2009) that the purpose of travelling is common among ELT teachers especially among NESTs and Romanowski and Nasser (2015) consider it generally as part of the professional life of expatriate faculty. This implies that members within the English Department do not all pursue similar goals that are inspired by their shared profession, which negatively affects the establishment of a group identity. As T16 stated above, such short-term objectives make individuals unable to compromise their personal values in favor of group-based values. Unity of purpose where self-interest is defined in terms of the group is a key element of social identity (van Knippenberg \& Hogg, 2003).

In line with this, the findings also suggest that some teachers leave CAS-1 because of the unappealing location of this campus. CAS-1 is located in a town far from the capital and its 
underdeveloped status makes it unattractive to non-Omani teachers especially the Western teachers who are outsourced as opposed to other non-Omanis who do not find adjustment very difficult.

... [CAS-1] is difficult to recruit for ... we are in the middle of nowhere. Maybe in the English world, people want to live of course in the bigger cities. [T7, member, American, outsourced]

I have actually heard teachers say this, that '[the town] doesn't even have a swimming pool, what do we do?' So, culturally probably that is a big difference... Probably that is also one of the reasons why they don't want to stay on. [T15, member, Indian, MoHE-fixed]

This contradicts findings by Khan (2011) who reports that non-Omani staff members enjoy life on campus. In Khan's study, however, the campus was provided with facilities such as 'a swimming pool' that helps staff adjust to the Omani context. Such a finding reinforces the fact that individual motivations rather than group-based pertain in the Department which has implications for the Omanisation priorities. While cultural diversity is an asset, its association with instability hinders building capacity at the specific CAS-1 site and calls for localizing workforce. In fact, the literature in relation to the GCC suggests that wider utilization of local human resources is key towards achieving knowledge-based economy which is the current goal of higher education (Randeree, 2008).

\section{The Costs of Group Instability}

The interaction between staff cultural diversity and the management practices outlined above seems to hinder the establishment of shared norms. The SIA suggests that group norms are the 'shared cognitive representations that, within a particular context, characterize the behavior of members of relevant out-groups and describe and prescribe the behavior of in-group members including ourselves' (Hogg \& Reid, 2006, 10). Norms, thus, are the essence of identities (Kreindler et al., 2012) that underlie a group's prototype. At the English Department level, the diversity in ideologies and norms that are associated with the cultural diversity of the staff appears to influence the attitudes of teachers towards the ELT prototype functioning at the English Department.

This increases the demands on leadership, as leaders have to develop an awareness of the different perspectives and be able to deal with such variability bearing in mind the centralized nature of the system. T2 mentioned that these differences manifest in how teachers approach teaching at the English Department.

... you have Omanis and then you have foreigners... so you will feel when you deal with them that some of them will have different educational backgrounds... [the] British educational way of handling the projects is different from the American way... you feel that they see things in different ways. [T2, leader, Omani, MoHE-permanent]

The differences in norms also translate into different preferable methods of teaching that could be culturally unwelcomed in the context of CAS-1. By means of illustration, the formal classroom-based style of teaching at CAS-1 seemed to upset an American teacher who maintained that

'... in America, in the colleges, teachers would have connections with the other teachers where 'everybody, lets go to the park and we will have a class in the park' and that builds a rapport with the teacher... we need to change the system. We can't just have 'here is the book go teach it'. [T7, member, American, outsourced] 
T7's view is inconsistent with the Omani norms where formality in education is necessary for regulating relations especially between genders. The Social Identity Theory suggests that perception of belonging to one group that forms a basis for social identity results in a consensus on the evaluations members have of the group (Tajfel \& Turner, 1979). This did not seem to be the case in the Department as the outsider's perspective is evident in the narratives of the international staff. Haslam (2004) points out that in intragroup context, members could perceive themselves based on their distinct personal identities and in such case, they refuse to accept other group members telling them what to do.

Another perceived demonstration of the inconsistent understandings of the academic culture is the different ways of assessing the performance of students. There was a perception that nonOmani teachers tended to assign high scores to students, which was partially attributed to the different academic cultures teachers identify with. Such inconsistency was perceived to hinder teamwork among teachers and increase anxiety when this mode of work was used.

There are certain people here who just don't like marking with other people because it always causes anxiety... People are always worried about the other teacher they are going to mark with. [T8, member, British, outsourced]

Longevity within a group is key for value conversion towards cohesion and high turnover reduces the shared history between group members, which affects social group formation (E. Ashforth \& Mael, 1989). Instability at the English Department thus hinders establishing a cohesive academic/ professional culture that could bring perspectives closer as T16 stressed.

... you can't build new teams every year with teachers who know the work ... and others [who] don't know the work and some of them are resistant to the new academic culture. ... that is one obstacle to successful teamwork. [T16, member, Tunisian, MoHE-fixed]

Generally, identification with a group is driven by a motivation to achieve distinctiveness (Horton et al., 2014) and positive self-evaluation (Koivisto \& Rice, 2016). Identification with a group is also related to job satisfaction and willingness to remain in an organization (Avanzi et al., 2014). Hence, people seek identification with groups that respond to their motivations. The structure created at the English Department based on the different employment modes restricts mobility between the impermeable employment categories. The presence of such structure motivates individuals to leave the group to join other groups (Finley, 2010; Haslam, 2004).

Being in charge of the group, the leaders at the English Department reported being pressured by such instability because they repeatedly had to deal with new teachers and explain the ELT prototype to them. T9 and T7 expressed that the number of teachers joining the English Department could be so large that it could outpace the ability of team leaders to provide adequate induction to the courses.

...I came, I landed in Muscat. They dropped me at school, they handed me books: 'teach this'. There was no orientation, there was no introduction, there was no watching of a class ... there was just like kind of 'here is what you are doing, here is your books, good luck'. [T7, member, American, outsourced]

The lack of induction happened when teachers joined during the semester to replace a teacher who left the department some time into the semester. Induction was seen as a requirement that could enable teachers to learn the prototype of ELT at CAS. Furthermore, the unstable team composition made team leaders face the challenge of varied levels of professionalism among teachers a explained by $\mathrm{T} 4$. 
... sometimes as a coordinator you will take over your shoulder to cover classes ... you have to take the responsibility of ensuring that everything related to the students...[is] documented and then transferred to the substitute teacher... [T4, leader, Omani, MoHE-permanent]

The lack of stability seems to have implications at the level of other group dynamics. The findings suggest that it relates to poor communication, high conflict rate, and limited collaboration between teachers as elaborated more on in Al Muqarshi, Kaparou, \& Kelly (2020). Tuckman (1965) explains that the life of a team goes through four stages: forming, storming, norming, and performing. The instability characterizing the English Department seems to make it go through this process repeatedly and to less effectively complete the norming and performing stages.

\section{Discussion and conclusions}

Oman's 2040 vision places a considerable emphasis on maintaining the Omani identity. This study illustrates how recruiting non-Omanis and especially NESTs could become a threat to establishing a unified identity, given the current management practices. Looking outward, however, Oman cannot function in isolation of the world that is rapidly globalizing. With the constantly blurring boundaries between countries and the increasing recruitment of international faculty members, the effectiveness of the process of Omanisation remains questionable. In fact, the globalization of ideas and values has overpassed all constraints. To reach a middle ground between these demands, a collective professional identity that invests in the value of multiplicity should be encouraged.

Nonetheless, van Knippenberg and Haslam (2003) argue that a level of homogeneity in certain aspect that could define a common category is a prerequisite for making use of informational diversity. This suggests that making use of cultural diversity in the academic context necessitate establishing a level of cohesion that is inspired by a shard prototype. The SIA sees group's prototype as context-specific and inspired partially by the history of the ingroup (van Knippenberg \& Hogg, 2003). Thus, prototypes and their effects within organizational groups must not be seen as instant nor static but are accumulative, emergent and influenced by the time spent within a group. Furthermore, based on the premise that a group prototype is consensual and should be regularly adapted as Hogg and Reid (2006) suggest, a group's identity should be seen as emergent and could constantly be reconfigured. For such a collective identity within the Omani HE context, the findings of the current study suggest that attention needs to be paid to two key areas: staff selection and staff retention.

As in any other EFL contexts, recruiting a number of qualified NESTs could be a healthy quality practice. However, the associated instability makes overreliance on NESTs a hindrance against sustaining human capital (Waxin \& Bateman, 2016). Human capital is the key for creating knowledge-based economy as it creates the knowledge infrastructure and function as the intelligent force that runs educational systems. Hence, it is neither being Omani nor being NEST that should be given precedence in selecting faculty members. Rather, it should be the competence created through education which directly feeds into building an intellectual capital (Khalique et al., 2011). Attracting talented and qualified academics is the means for creating knowledge, which reinforces the role of HE in achieving the Omani 2040 vision. However, as the pressure for nationalizing capacity pertains, a quota-based system that prioritizes qualification in recruitment has the potential to respond to both the local and the global pressures in a way that advantages higher education and facilitate building an intellectual capital. 
Furthermore, as capital creation through managing talents is an accumulative process, staff retention should be a priority for HEIs (Abdullah \& Abubakar, 2017). The findings of this study point out that managing human resources' attitudes requires establishing a common prototype that pushes them to serve the interest of the group. Research suggests that longevity within a group is key for identifying with the group's prototype due to the role time plays in aligning faculty members' values to serve a common objective. In their study to measure identification level amongst alumni in a religious school, Meeussen et al. (2014) conclude that after some time, a difference in the value fit of the low diversity groups appeared, which indicates that there was a value convergence over time which was moderated by the extent of diversity within a group.

In another study, Fielding and Hogg (1997) conducted a naturalistic study where 13 groups (each composed of 11 mixed-sex participants on average) spent three weeks together. The researchers report that over time, social identification, perceived leadership effectiveness, and social attraction increased and they explain that by the increase in cohesion within the group over time. Haslam \& Platow (2001) also concluded after an experimental study that that only after followers have had some earlier knowledge and familiarity with the leader that they would support him/her seemingly because they develop trust in the leader over time.

The implication of these studies, and the current research's findings, for the Omani higher education is that the temporal dimension of group prototypes is key for prototype establishment and functioning. The time spent within a group is also important for leadership to get the support of followers.

This study is an original contribution to the scarce literature that sheds light at human resource management in higher education from a social/psychological perspective. It is especially relevant to the GCC context that is highly dependent on international workforce but is aiming to increase dependence on local workforce. While such nationalization efforts are indispensible for sound human and social development, they are not without limitations. Careful strategic thinking that aligns HE priorities with national priorities is the only way towards bridging the gap between education and economy. Furthermore, the study integrates aspects from social identity theory, human resource management theory and the findings of the research conducted to establish that the mere aggregation of talents does not serve the pivotal role of higher education in the Omani context. The management of such a composition extends far beyond the recruitment stage. A collective identity establishment requires a strategic thinking that celebrates difference but also acknowledges and reinforces a level of similarity. The Gulf Cooperation Countries need to pay attention to the side affects that their human resources management policies and practices create to the identity of the workplace. Unless they reconsider their priorities that could lead to achieve their visions, the fluid workplace environment will continue to function as a hindrance against long-term results; the knowledge-based economy.

\section{References}

Abbas, A. (1995). Cultural discontinuity and Arab management thought. International Studies of Manangement \& Organizations, 25(3), 7-30. https://doi.org/10.2307/40397307

Abdullah, H., \& Abubakar, A. (2017). Strategic Talent Management Practices for Higher Institutions Strategic Talent Management Practices for Higher Institutions. January 2017.

Al-Hamadi, A., Budhwar, P., \& Shipton, H. (2007). Management of human resources in Oman. The International Journal of Human Resource Management, 18(January), 100- 
113. https://doi.org/10.1080/09585190601068383

Al-Issa, A. (2005). The role of English language culture in the Omani language education system: an ideological perspective. Language, Culture and Curriculum, 18(3), 258-270. https://doi.org/10.1080/07908310508668746

Al-Issa, A. (2006). The Cultural and Economic Politics of English Language Teacing in Sultanate of Oman. The Asian EFL Journal Quarterly, 8(1), 194-218.

Al-Mahrooqi, R., \& Tuzlukova, V. (2014). English communication skills and employability in the Arabian Gulf: The case of Oman. Pertanika Journal of Social Science and Humanities, 22(2), 473-488.

Al'Abri, K. (2011). The impact of globalization on education policy of developing countries: Oman as an example. Literacy Information and Computer Education Journal (LICEJ), 2(4), 491-502.

Al Balushi, A. (2012). Leadership of private universities and colleges in the Sultanate of Oman. Doctoral dissertation, University of Southampton.

Al Muqarshi, A., Kaparou, M., \& Kelly, A. (2020). Managing cultural diversity for collective identity: A case study of an ELT department in Omani higher education. Educational Management Administration \& Leadership, 1741143220921187. https://doi.org/10.1177/1741143220921187

Anderson, C., \& Brown, C. (2010). The functions and dysfunctions of hierarchy. In Research in Organizational Behavior (Vol. 30, Issue C, pp. 55-89). https://doi.org/10.1016/j.riob.2010.08.002

Ashforth, B., \& Johnson, S. (2001). Which hat to wear? The relative salience of multible identities in organizational contexts. In M. Hogg \& D. Terry (Eds.), Social identity processes in organizational contexts (pp. 31-48). Psychology Press.

Ashforth, E., \& Mael, F. (1989). Social identity theory and the organization. The Academy of Management Review, 14(1), 20-39.

Avanzi, L., Fraccaroli, F., Sarchielli, G., Ullrich, J., \& van Dick, R. (2014). Staying or leaving: a combined social identity and social exchange approach to predicting employee turnover intentions. International Journal of Productivity and Performance Management, 63(3), 272-289. https://doi.org/10.1108/IJPPM-02-2013-0028

Blackwell, L., Snyder, L., \& Mavriplis, C. (2009). Diverse faculty in STEM fields: Attitudes, performance, and fair treatment. Journal of Diversity in Higher Education, 2(4), 195205. https://doi.org/10.1037/a0016974

Christians, C. (2008). Ethics and politics in qualitative research. In N. Denzin \& Y. Lincoln (Eds.), The landscape of qualitative research (3rd ed., pp. 185-220). SAGE Publications Ltd.

Clarke, M., Hyde, A., \& Drennan, J. (2013). Professional identity in higher education. In The Academic Profession in Europe: New Tasks and New Challenges (Vol. 5, pp. 7-21). https://doi.org/10.1007/978-94-007-4614-5_2

Cole, M., \& Bruch, H. (2006). Organizational identity strength, identification, and commitment and their relationships to turnover intention: does organizational hierarchy matter? Journal of Organizational Behavior, 27(5), 585-605. https://doi.org/10.1002/job.378

Creswell, J. (2014). Research design (4th ed.). SAGE Publications Ltd. 
Dickson-Swift, V., James, E., \& Liamputtong, P. (2008). Undertaking sensitive research in the health and social sciences: managing boundaries, emotions, and risks. Cambridge University Press.

Donn, G., \& Issan, S. (2007). Higher Education in Transition: Gender and Change in the Sultanate of Oman. Scottish Educational Review, 39(2), 173-185.

Ellemers, N., De Gilder, D., \& Haslam, A. (2004). Motivating individuals and groups at work: a social identity perspective on leadership and group performance. In Academy of Management Review (Vol. 29, Issue 3, pp. 459-478). https://doi.org/10.5465/AMR.2004.13670967

Fielding, K., \& Hogg, M. (1997). Social identity, self-categorization, and leadership: a field study of small interactive groups. Group Dynamics: Theory, Research, and Practice, $1(1), 39-51$.

Finley, S. A. (2010). An identity-based understanding of intergroup conflict. Contemporary Justice Review: Issues in Criminal, Social, and Restorative Justice, 13(4), 425-441. https://doi.org/10.1080/10282580.2010.517977

Gillham, B. (2000). Case study research methods. Continuum International Publishing Group. https://doi.org/10.1007/s13398-014-0173-7.2

Haslam, S. (2004). Psychology in organizations: the social identity approach (Second). SAGE Publications Ltd.

Haslam, S., \& Platow, M. (2001). The link between leadership and followership: how affirming social identity translates vision into action. Personality and Social Psychology Bulletin, 27(11), 1469-1479. https://doi.org/10.1177/01461672012711008

Hentschel, T., Shemla, M., Wegge, J., \& Kearney, E. (2013). Perceived diversity and team functioning: the role of diversity beliefs and affect. Small Group Research, 44(1), 33-61. https://doi.org/10.1177/1046496412470725

Hogg, M. (2001). A social identity theory of leadership. Personality and Social Psychology Review, 5(3), 184-200.

Hogg, M. (2005). Social identity and misuse of power: the dark side of leadership. Brooklyn Law Review, 70(4), 1239-1257.

Hogg, M., \& Reid, S. (2006). Social identity, self-categorization, and the communication of group norms. Communication Theory, 16(1), 7-30. https://doi.org/10.1111/j.14682885.2006.00003.x

Hornsey, M. (2008). Social identity theory and self-categorization theory: a historical review. Social and Personality Psychology Compass, 2, 204-222. https://doi.org/10.1111/j.17519004.2007.00066.x

Horton, K., McClelland, C., \& Griffin, M. (2014). Defined by our hierarchy? How hierarchical positions shape our identifications and well-being at work. Human Relations, 67(10), 1167-1188. https://doi.org/10.1177/0018726713516374

Jackson, C., \& Sherriff, N. (2013). A Qualitative approach to intergroup relations: exploring the applicability of the social identity approach to "messy" school context. Qualitative Research in Psychology, 10, 259-273.

Joarder, M., Subhan, M., Ghani, A., \& Islam, R. (2015). Pay, security, support and intention to quit relationship among academics in developing economy. Investment Management and Financial Innovations, 12(3), 190-199. 
Kelly, A. (2009). In defence of anonymity: rejoining the criticism. British Educational Research Journal, 35(3), 431-445. https://doi.org/10.1080/01411920802044438

Khalique, M., Shaari, J., \& Isa, H. A. (2011). Intellectual capital and its major components. 3(1997), 343-347.

Khan, S. (2011). Factors affecting the motivation of expatriate English as a forign language (EFL) teachers in the Sultanate of Oman. University of Exeter.

Koivisto, S., \& Rice, R. (2016). Leader prototypicality moderates the relation between access to flexible work options and employee feelings of respect and leader endorsement. International Journal of Human Resource Management, 27(22), 2771-2789. https://doi.org/10.1080/09585192.2015.1126337

Kreindler, S., Dowd, D., Dana Star, N., \& Gottschalk, T. (2012). Silos and social identity: the social identity approach as a framework for understanding and overcoming divisions in health care. In Milbank Quarterly (Vol. 90, Issue 2, pp. 347-374). https://doi.org/10.1111/j.1468-0009.2012.00666.x

Lee, R. (1993). Doing research on sensetive topics. SAGE Publications Ltd.

Lo, W. (2010). Decentralization of higher education and its implications for educational autonomy in Taiwan. Asia Pacific Journal of Education, 30(2), 127-139. https://doi.org/10.1080/02188791003721572

Meeussen, L., Schaafsma, J., \& Phalet, K. (2014). Fast track report when values (do not) converge: cultural diversity and value convergence in work groups. 528(August 2013), 521-528.

Mercer, J. (2007). The challenges of insider research in educational institutions. Oxford Review of Education, 33(1), 1-17.

Ministry of Higher Education. (2015). CAS Strategic Plan (Phase 2) (p. 1).

Neal, M. (2010). When Arab-expatriate relations work well: Diversity and discourse in the Gulf Arab workplace. Team Performance Management, 16(5/6), 242-266. https://doi.org/10.1108/13527591011071331

Peterson, J. (2011). Oman faces the twenty-first century. In M. Tetreault, G. Okruhlik, \& A. Kapiszewski (Eds.), Political change in the Arab Gulf states: stuck in transition (pp. 99118). Lynne Rienner Publishers.

Randeree, K. (2008). Challenges in human resource management and organisational development in the Arabian Gulf: An analysis of national identity and diversity. International Journal of Interdisciplinary Social Sciences, 2(5), 49-55. http://www.scopus.com/inward/record.url?eid=2-s2.080051512552\&partnerID=40\&md5=b13b5b823e4d7d0a121d2f03ed165ee 1

Romanowski, H., \& Nasser, R. (2015). Identity issues: expatriate professors teaching and researching in Qatar. Higher Education, 69(4), 653-671. https://doi.org/10.1007/s10734014-9795-0

Saldana, J. (2016). The coding manual for qualitative researchers (Third ed.). SAGE Publications Ltd.

Schmaling, K., Trevino, A., Lind, J., Blume, A., \& Baker, D. (2014). Diversity statements: how faculty applicants address diversity. Journal of Diversity in Higher Education, December(22), 1-12. https://doi.org/10.1037/a0038549 
Steffens, N., Haslam, S., Reicher, S., Platow, M., Fransen, K., Yang, J., Ryan, M., Jetten, J., Peters, K., \& Boen, F. (2014). Leadership as social identity management: introducing the identity leadership inventory (ILI) to assess and validate a four-dimensional model. Leadership Quarterly, 25(5), 1001-1024. https://doi.org/10.1016/j.leaqua.2014.05.002

Tajfel, H., \& Turner, J. (1979). An integrative theory of intergroup conflict. In W. G. Austin \& S. Worchel (Eds.), The Social Psychology of Intergroup Relations (pp. 33-47). Monterey, CA: Brooks/Cole.

Tatli, A., \& Özbilgin, M. F. (2012). An emic approach to intersectional study of diversity at work: a Bourdieuan framing. International Journal of Management Reviews, 14(2), 180200. https://doi.org/10.1111/j.1468-2370.2011.00326.x

Tuckman, B. (1965). Developmental sequence in small groups. Psychological Bulletin, 63(6), 384-399.

van Knippenberg, D., \& Haslam, S. (2003). Realizing the diversity dividend: exploring the subtle interplay between identity, ideology, and reality. In S. Haslam, D. van Knippenberg, M. Platow, \& N. Ellemers (Eds.), Social identity at work: developing theory for organizational practice (pp. 61-80). Psychology Press.

van Knippenberg, D., \& Hogg, M. (2003). A social identity model of leadership effectiveness in organizations. Research in Organizational Behavior, 25(03), 243-295. https://doi.org/10.1016/S0191-3085(03)25006-1

van Knippenberg, D., \& Schippers, M. (2007). Work group diversity. Annual Review of Psychology, 58(1), 515-541. https://doi.org/10.1146/annurev.psych.58.110405.085546

Warner, L. (2008). A best practices guide to intersectional approaches in psychological research. In Sex Roles (Vol. 59, Issues 5-6, pp. 454-463). https://doi.org/10.1007/s11199-008-9504-5

Waxin, M.-F., \& Bateman, R. (2016). Labour localisation and human resource management practices in the Gulf countries. In P. Budhwar \& K. Mellahi (Eds.), Handbook of Human Resource Management in the Middle East. https://doi.org/10.4337/9781784719524.00026

Wong, C.-Y. (2009). Are native speakers "good" language instructors? A case study of untrained ESL tutors. ARECLS, 6(c), 122-140.

Zerovec, M., \& Bontenbal, M. (2011). Labor nationalization policies in Oman: implications for Omani and migrant women workers. Asian and Pacific Migration Journal, 20(3-4), 365-387. https://doi.org/10.1177/011719681102000306 